\title{
Exergoeconomic effect of adding a new feedwater heater to a steam power plant
}

\author{
Amin Mohammadi Khoshkar Vandani ${ }^{1}$, Fatemeh Joda ${ }^{1}$, Fatemeh Ahmadi ${ }^{1}$ \\ and Mohammad Hossein Ahmadi ${ }^{2, a}$ \\ 1 Faculty of Mechanical \& Energy Engineering, Shahid Beheshti University, A.C., Tehran, Iran \\ 2 Department of Renewable Energies, Faculty of New Sciences and Technologies, University of Tehran, Tehran, Iran
}

Received 16 March 2016, Accepted 13 September 2016

\begin{abstract}
Steam power plants play a key role in electricity generation throughout the world. Their performance is strongly dependent on the boilers performance and feedwater heater network. In this study, exergoeconomic analysis is performed on a steam power plant in Iran and effects of adding a new feedwater heater to the cycle are investigated through exergy and exergoeconomic analyses. In this respect, two configurations are considered, in the first one the new feedwater heater is placed before the first existing feedwater heater and in the second configuration, the new feedwater heater is placed after the last one. Performance of the system in these two new configurations is studied and then compared with the base case condition. Also an optimization algorithm is applied to each configuration and the base case condition. The results show that boiler has the highest rate of exergy destruction. Also in terms of exergoeconomic analysis, boiler has a high value of relative cost different which $45 \%$ of it is because of exergy destruction cost. Comparison between the results shows that adding the new feedwater heater increases the exergy efficiency of the plant, but if it placed after the last feedwater heater, it can reduce the product cost rate of the plant as well. Optimization results reveal that placing the new feedwater heater in this position can reduce the product cost rate by $0.16 \%$ and increase the exergy efficiency by $0.33 \%$.
\end{abstract}

Key words: Steam power plant / feedwater heater / exergoeconomy / efficiency / optimization

\section{Introduction}

Electricity is an important form of energy the generation of which is increased in the last decades, due to population growth and improved technology. Based on EIA ${ }^{1}$ statics, electricity generation is increased from 8 billion $\mathrm{MWh}_{\mathrm{e}}$ in 1980 to 21.5 billion $\mathrm{MWh}_{\mathrm{e}}$ in 2012. There are many different ways to generate electricity. Steam power plant is one of the most conventional methods in which superheated steam is produced in a boiler and then expands in a turbine to generate power. The power is used in a generator to produce electricity. Different sources of energy can be used to heat the water, including oil, natural gas, coal, nuclear energy, geothermal energy, etc.

Over the years, many researchers have tried to improve the performance of steam power plants. To do so, second law efficiency seems a better criterion. This is because that in the first law, heat transfer to the

\footnotetext{
a Corresponding author:

mohammadhosein.ahmadi@gmail.com

1 Energy Information Administration.
}

environment is the only possible way for energy dissipation. But in exergy analysis, irreversibility of the system is taking into account as well. Therefore, exergy is a better indicator of the system performance.

Hongbin et al. [1] performed exergy analysis on a steam power plant and calculated exergy destruction and exergy efficiency of each component of the system. They showed that boiler with $91.6 \%$ has the highest share of exergy destruction in the plant. Aljundi [2] performed energy and exergy analyses on a steam power plant in Jordan and analyzed system components separately to calculate the highest energy and exergy losses in the plant. Also the effect of varying ambient temperature on the plants performance was studied. The results showed that the highest energy and exergy losses occur in the condenser and boiler, respectively. Rosen et al. [3] tried to decrease irreversibilities of a coal-fired steam power plant. They reduced the fraction of excess air in combustion process and also decreased the temperature of stack outlet flue gases. The results showed that if the fraction of excess combustion air and stack-gas temperature from 0.4 and $149{ }^{\circ} \mathrm{C}$ decreases to 0.15 and $87^{\circ} \mathrm{C}$, respectively, exergy 


\section{Nomenclature}

\begin{tabular}{|c|c|}
\hline$\dot{C}$ & Flow cost rate (\$/year) \\
\hline$c$ & Cost per unit exergy $(\$ / G J)$ \\
\hline$C R F$ & Capital recovery factor \\
\hline$\dot{E x}$ & Exergy $(\mathrm{kW})$ \\
\hline$e x$ & Specific exergy $\left(\mathrm{kJ} \mathrm{kg}^{-1}\right)$ \\
\hline$\dot{E} x^{D}$ & Exergy destruction $(\mathrm{kW})$ \\
\hline$f$ & Exergoeconomic factor $(\%)$ \\
\hline$h$ & Enthalpy $\left(\mathrm{kJ} . \mathrm{kg}^{-1}\right)$ \\
\hline$h r$ & Hour \\
\hline$i$ & Interest rate $(\%)$ \\
\hline$L H V$ & Lower heating value $\left(\mathrm{kJ} \cdot \mathrm{kg}^{-1}\right)$ \\
\hline$\dot{m}$ & Mass flow rate $\left(\mathrm{kg} . \mathrm{s}^{-1}\right)$ \\
\hline$N$ & Plant life time (year) \\
\hline$R$ & Universal gas constant \\
\hline$r$ & Relative cost difference (\%) \\
\hline$s$ & Entropy $\left(\mathrm{kJ} \cdot \mathrm{kg}^{-1} \cdot \mathrm{K}^{-1}\right)$ \\
\hline$T$ & Temperature $\left({ }^{\circ} \mathrm{C}\right)$ \\
\hline$T_{0}$ & Ambient temperature \\
\hline$\dot{W}$ & Power $(\mathrm{kW})$ \\
\hline$y$ & Molar fraction \\
\hline$\dot{Z}$ & Capital cost rate $(\$ /$ year $)$ \\
\hline$Z$ & Component purchase cost $(\$)$ \\
\hline \multicolumn{2}{|r|}{ Greek symbols } \\
\hline$\xi$ & Chemical exergy/energy ratio \\
\hline$\varphi$ & Maintenance factor \\
\hline$\psi$ & Exergy efficiency \\
\hline \multicolumn{2}{|r|}{ Subscript } \\
\hline $\mathrm{ch}$ & Chemical \\
\hline Cond & Condenser \\
\hline FWH & Feed water heater \\
\hline ph & Physical \\
\hline $\mathrm{ST}$ & Steam turbine \\
\hline
\end{tabular}

efficiency of the plant increases by $4.1 \%$. Rosyid et al. [4] studied a steam power plant two-stage binary cycle in terms of energy and exergy. They investigated the effect of variations in steam power plant operational load and condenser cooling water temperature, turbine inlet temperature and turbine inlet pressure on the performance of the total cycle. Based on the results; reducing the steam turbine load from $100 \%$ to $25 \%$ leads to a $0.97 \%$ decrease in the plant's efficiency. Vandani et al. [5] performed energy and exergy analyses on a boiler blow down heat recovery system. They also optimized the plants performance to increase its exergy efficiency. The results indicated that $0.72 \%$ increase in exergy efficiency of the plant could be achieved using heat recovery technique. Xu et al. [6] proposed a new system in which a steam ejector is used to integrate a steam power plant and a $\mathrm{CO}_{2}$ capture system. Using the proposed method, surplus energy of the extracted steam is recovered and therefore the reduction in output power of the steam turbine decreases. Also energy loss in carbon capture process is reduced and total plants efficiency is increased. Singh et al. [7] coupled a Kalina cycle to a steam power plant to recover the waste heat of the exhaust gases and optimized the plant's performance. The results showed that for each operating pressure, there is an optimum ammonia mass fraction which yields the maximum cycle efficiency. In general, as turbine inlet pressure increases, the plant's efficiency increases, but it also increases the difficulty in operation of the system. Therefore a moderate pressure is more suitable for the plant. Suresh et al. [8] studied a supercritical (SupC) and an ultrasupercritical (USC) steam power plant and optimized the plant's performance. Exergy efficiency of the optimized SupC and USC power plants showed $2.6 \%$ and $4.8 \%$ increase, respectively. Also $\mathrm{CO}_{2}$ reduction is reduced by $6 \%$ and $11 \%$ in the selected power plants. They also compared the effect of high and low ash coal on the system performance. Li et al. [9] studied the effect of condenser pressure on exergy efficiency of the plant in subcritical, supercritical, and ultrasupercritical steam power plants. Xu et al. [10] compared two schemes of extraction steam in a double reheat ultrasupercritical power plant based on thermodynamics and economics under part-load and full-load operations, where one scheme adopts outer steam coolers and the other employs a regenerative turbine. The results showed that the regenerative turbine has a better effect on the system performance. The amount of saved energy is higher under part-load conditions.

Although exergy is a good criterion for analyzing energy systems, but it doesn't take into account the economic aspects of the system. To solve this issue, exergy and economic analyses are combined together to form the exergoeconomic analysis. Ozdemir et al. [11] carried out an exergoeconomic analysis on a fluidized-bed coal combustor steam power plant. The results showed that the plant has an exergy efficiency of $20.28 \%$ and the unit cost of the produced steam is found to be $1.397 \mathrm{c} / \mathrm{kg}$. They suggested that an air preheater between ventilation fan and fluidized-bed coal combustor can significantly decrease exergy destruction of the plant. Matawala et al. [12] analyzed a $50 \mathrm{MW}$ steam power plant exergoeconomically. The considered plant also applied a vapor absorption refrigeration system for its low temperature applications. Two different heat sources for the refrigeration cycle were considered, including steam generated in an independent boiler and an extraction steam from the steam turbine. Costs of these methods were compared together. Manesh et al. [13] applied exergy, exergoeconomic and pinch analyses on two steam power plants in Iran, simultaneously. They also defined two new variables as exergy destruction level and exergy cost destruction level and introduced a new graphical representation to show performance of each component based on exergoeconomic analysis. Ameri et al. [14] carried out an exergoeconomic evaluation of a steam power plant. They calculated exergy destruction and exergy efficiency of each component and also studied the effects of the load variations and ambient temperature on exergy efficiency and irreversibility rates of the cycle. The results showed that load reduction leads to a decrease in exergy efficiency of the components. Mehrpanahi et al. [15] calculated thermo-economical parameters for repowering a steam power plant. They also computed cost 
of electricity generation in a repowered steam plant and compared it with those of a new gas turbine plant and a combined power plant. Ganjehkaviri et al. [16] developed a mathematical model to perform energy, exergy, exergoeconomic and exergoenvironmental analyses on a combined cycle power plant. The main focus of their work was to study the effect of vapor quality at steam turbine outlet. They considered three different objective functions including exergy efficiency, total cost rate of the system product and the $\mathrm{CO}_{2}$ emission. The results showed that an $88 \%$ quality at steam turbine outlet is the most realistic with respect to efficiency, economic and environmental aspects. Galanti et al. [17] represented a thermoeconomic analysis on an upgraded steam power plant which produces electricity and hydrogen. The proposed system is consisted of pyrolysis and gasification processes applied to an existing large steam power plant. Coal and biomass are fed to the system as fuel for both electricity and hydrogen production. The results showed that the gasification process is more expensive for large-sized hydrogen production because of higher capital costs. Khanmohammadi et al. [18] performed an exergoeconomic analysis on a steam power plant in Iran and calculated the cost of exergy destruction in each component. They studied the effect of main steam temperature, reheated steam temperature, condenser pressure and number of the feedwater heaters on the cycle performance. They showed that increasing the number of feedwater heaters leads to a decrease in the electricity price. Chacartegui et al. [19] developed a tool to investigate the performance of fossil fuel steam power plants under variable operating conditions or under maintenance operations. They predicted the behavior of the plant in different operating conditions of feedwater heaters, including different terminal temperature difference or drain cooler approach of the feedwater heaters, or under maintenance conditions, like a feedwater heater out of service. Farhad et al. [20] designed a method to reduce irreversibility of the feedwater heaters network in steam power plants based on pinch and exergy analyses. Applying this method leads to increase the exergy efficiency of the system components and the total system.

The aim of this study is to investigate the effect of adding a new feedwater heater to a steam power plant in terms of exergy and economy. In this respect, an actual steam power plant in Iran is considered and two different cases are defined to add the new feedwater heater. The exergoeconomic analysis is performed on both cases and the results are compared with the base case. Also using a sensitivity analysis, the most effective parameters on the system performance are identified and an optimization analysis is performed on the system to find the best achievable performance.

\section{System description}

Besat power plant, located in Tehran, Iran, is a steam power plant which has three units, each of which has a capacity of 82.5 MW. Flow diagram of the plant is shown in Figure 1. As could be seen, the plant has 5 feedwater heaters, including one open feedwater heater and 4 closed ones. Using these feedwater heaters, temperature of feedwater is increased before entering the boiler and therefore fuel consumption rate in boiler is decreased. Consequently, efficiency of the plant is augmented.

To provide the heat source needed to increase temperature of the feedwater, a stream is extracted from the turbine for each feedwater heater. The open FWH (FWH \#3) is more like a mixer which has the role of deaeration as well. Other FWHs can be considered as a shell and tube heat exchanger. Steam outlet of each FWH is fed to the previous FWH, except for the first one in which the outlet stream is fed to the condenser. A water cooled condenser is used in the plant. The cooling tower is not considered in this study.

Two different options are considered for adding the new feedwater heater to the system. In the first case, the new FWH is placed before FWH \#1. This scenario is presented in Figure 2. To provide the heat source, a new stream is extracted from the turbine. The other scenario is shown in Figure 3, in which the new FWH is set after FWH \#5.

\section{Mathematical Model}

\subsection{Exergy}

Exergy is the maximum work which can be obtained from a given form of energy using the environmental parameters as the reference state [21]. Exergy balance for a control volume is represented as follows:

$$
\dot{E} x^{Q}+\sum \dot{m}_{\text {in }} e x_{i n}=\dot{E x} x^{w}+\sum \dot{m}_{o u t} e x_{o u t}+\dot{E x} x^{D}
$$

where $\dot{E} x^{D}$ is the amount of destructed exergy in the component and $\dot{E} x^{Q}$ and $\dot{E x}{ }^{w}$ are the exergy associated to the heat transfer and work, respectively. The amount of these parameters are calculated as follows [22, 23]:

$$
\begin{aligned}
\dot{E} x^{Q} & =\left(1-\frac{T_{0}}{T_{r}}\right) \dot{Q} \\
\dot{E} x^{W} & =\dot{W}_{c . v} .
\end{aligned}
$$

In Equation (2), $T_{0}$ is the ambient temperature and $T_{r}$ is the temperature in which heat transfer is occurred.

Specific exergy is constituted of kinetic, potential, physical and chemical exergy. Neglecting the first two components, specific exergy could be defined as follows $[24,25]$ :

$$
e x=e x_{p h}+e x_{c h}
$$

Physical and chemical exergies are calculated as:

$$
\begin{aligned}
& e x_{p h}=\left(h-h_{0}\right)-T_{0}\left(s-s_{0}\right) \\
& e x_{c h}=\sum_{i=1}^{N} y_{i} e x_{i}^{c h}+R T_{0}\left(\sum_{i=1}^{N} y_{i} \ln ?\left(y_{i}\right)\right)
\end{aligned}
$$


A.M. Khoshkar Vandani et al.: Mechanics \& Industry 18, 224 (2017)

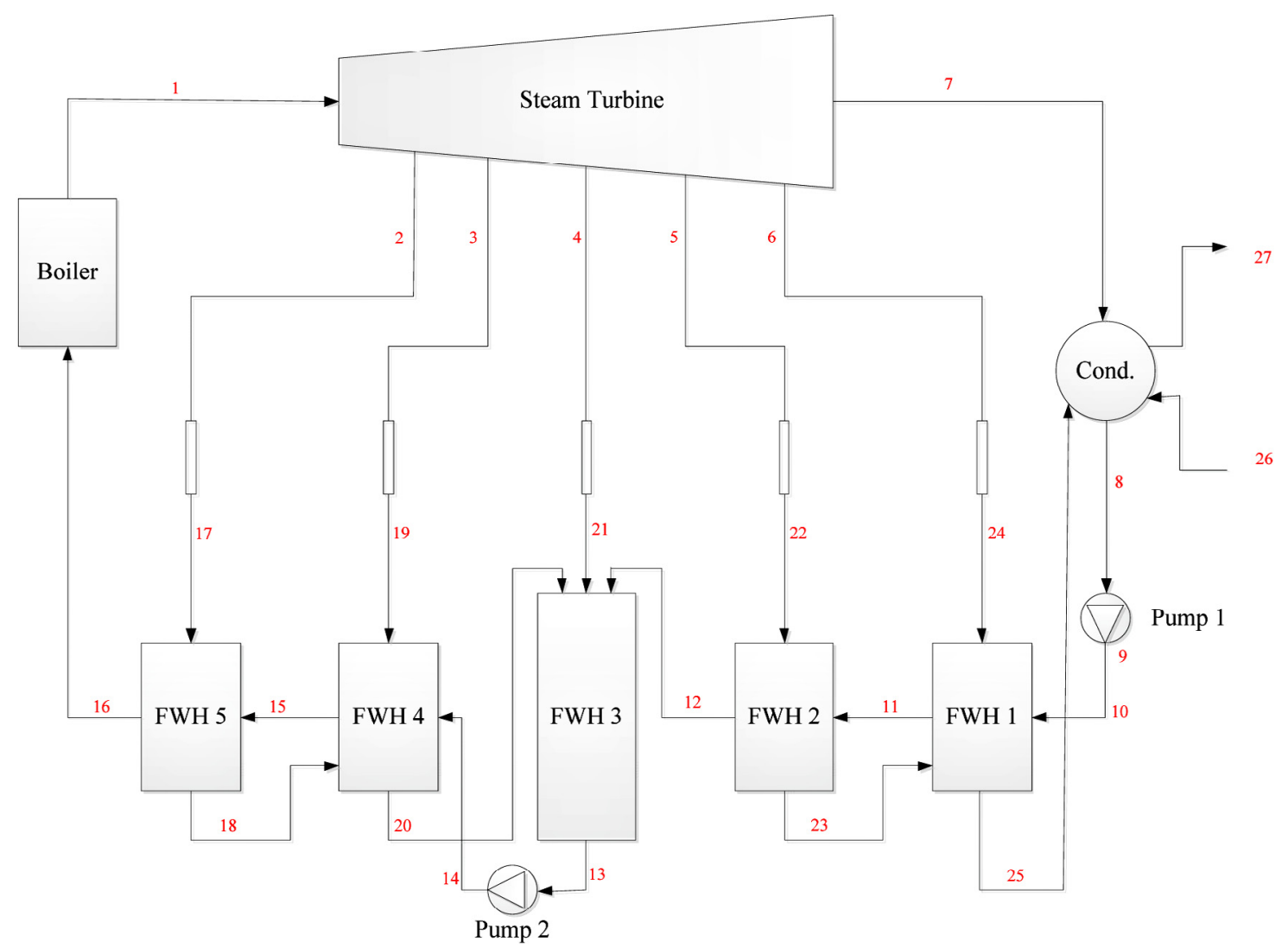

Fig. 1. Flow diagram of the considered plant (Base case).

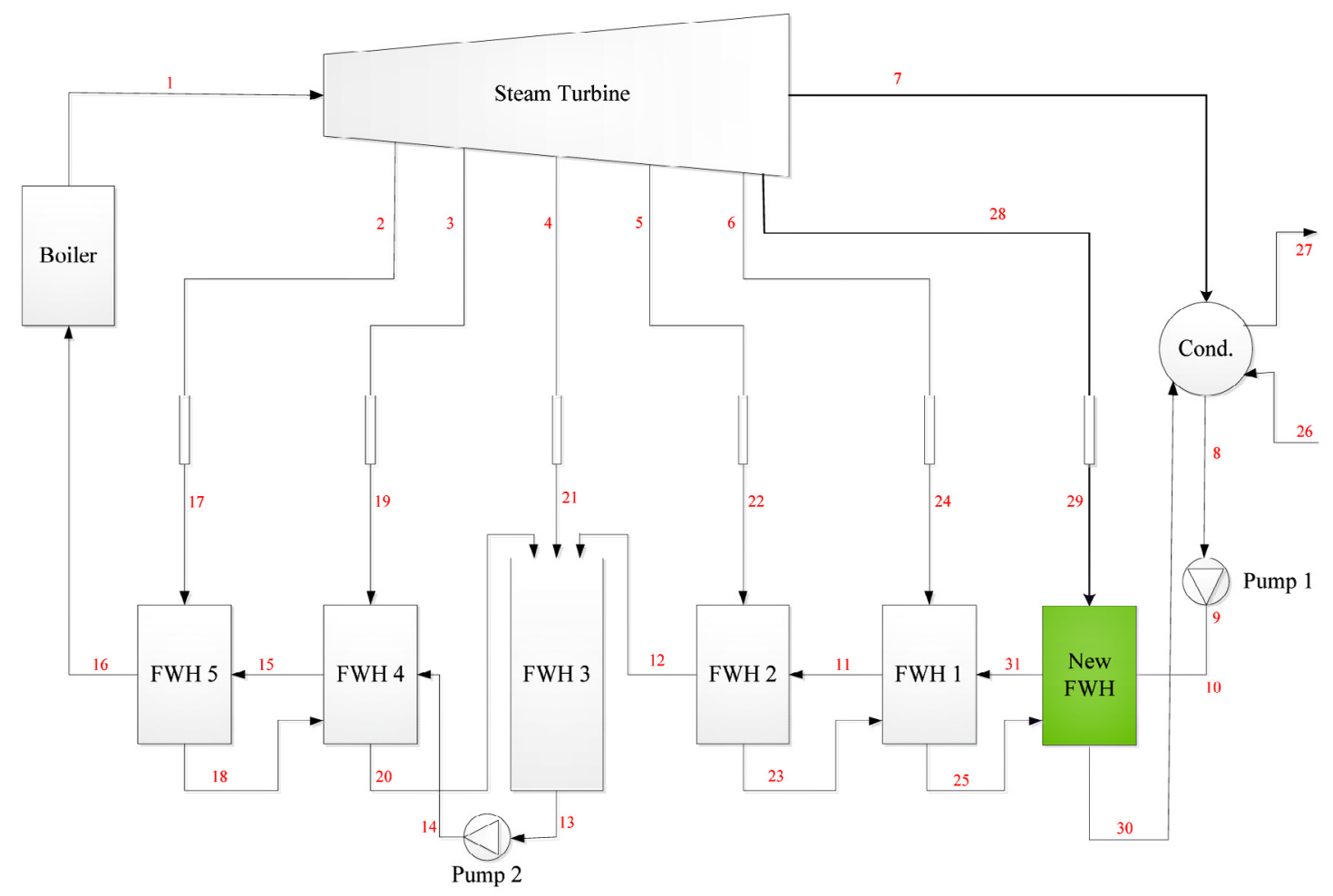

Fig. 2. Flow diagram of adding a new FWH (Case 1). 


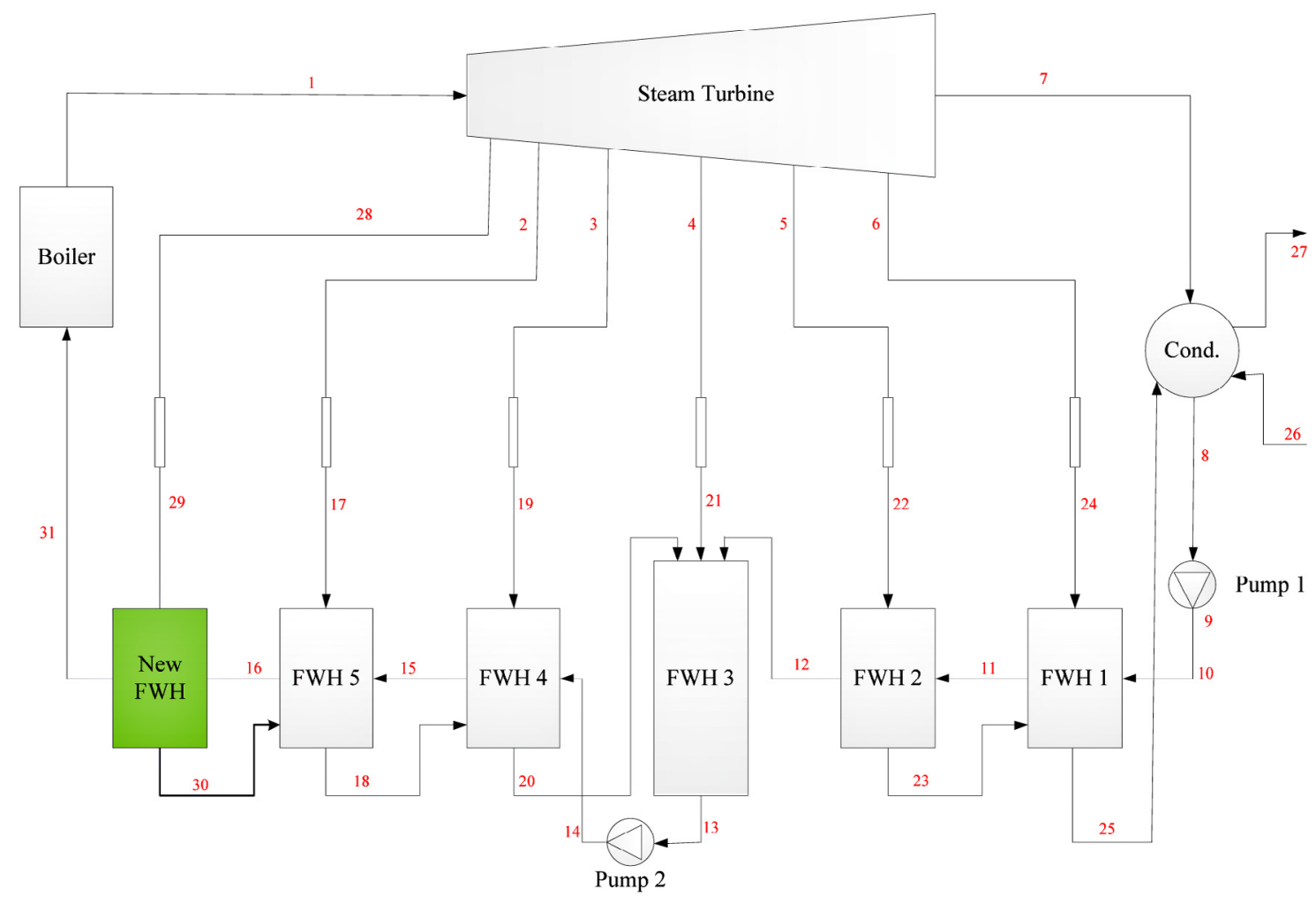

Fig. 3. Flow diagram of adding a new FWH (Case 2).

For calculating chemical exergy of fuels, the following simplified equation is used [23]:

$$
\xi=\frac{e x_{\text {fuel }}}{L H V_{\text {fuel }}}
$$

The value of $\xi$ is usually close to unity for the most of commonly used fuel gases [23]. For example, its value for methane and hydrogen are 1.06 and 0.985 , respectively.

Using the above equations, exergy destruction and exergy efficiency for each component could be easily computed. Table 1 shows the equations of exergy destruction and exergy efficiency for each component in the plant.

Total exergy destruction of the plant equals to the sum of exergy destruction of all the components.

\subsection{Exergoeconomy}

Exergoeconomic evaluation is a combination of both exergy analysis and economic principles. Performing this analysis provides some useful information about cost of each stream which is crucial for optimized design of the system. In exergoeconomic analysis, it is necessary to define the concepts of fuel and product exergies. The source which is consumed in a component to generate the product is defined as fuel. This is different with the actual fuel (such as natural gas, oil, coal, etc.) which is utilized in the plant. Also the product is the desired result generated by using the fuel.
Cost balance for a given control volume is expressed as:

$$
\begin{aligned}
\dot{C}^{Q}+\sum \dot{C}_{i n}+\dot{Z} & =\dot{C}^{W}+\sum \dot{C}_{\text {out }} \\
\dot{C} & =c \dot{E}
\end{aligned}
$$

In Equation (8), $\dot{Z}$ is the investment cost rate of the component and is equal to sum of the capital cost and the operation and maintenance costs. The investment cost rate of each component is computed as follows:

$$
\dot{Z}=\frac{Z . C R F \cdot \varphi}{h r}
$$

In this equation, $\varphi$ is the maintenance factor [22] and $h r$ is the total annual working hour of the plant. $C R F$ is the capital recovery factor which is expressed as follows:

$$
C R F=\frac{i(1+i)^{N}}{(1+i)^{N}-1}
$$

In this equation $i$ and $n$ are interest rate and plant's life time. Values of economical parameters are shown in Table 2.

Also, $Z$ is the investment cost of the component and its value is computed by equations given in Reference [14]. It should be noted that all used equations to evaluate capital cost of components are published in specific years. Therefore the estimated costs should be brought to the reference year using the Chemical Engineering Plant Cost Index (CEPCI) [26] to update all costs to the year 2013. 
A.M. Khoshkar Vandani et al.: Mechanics \& Industry 18, 224 (2017)

Table 1. Exergy destruction and exergy efficiency of each component in the power plant.

\begin{tabular}{|c|c|c|}
\hline Component & Exergy destruction & Exergy efficiency \\
\hline Feed Water Heater & $\dot{E} \dot{x}_{F W H}^{D}=\sum \dot{E} x_{\text {in }}-\sum \dot{E} x_{\text {out }}$ & $\psi_{F W H}=\frac{E x_{c o l d, \text { in }}-E x_{\text {cold }, o u t}}{E x_{b o t, i n}-E x_{b o t}}$ \\
\hline Steam turbine & $\dot{E} x_{S T}^{D}=\dot{E} x_{\text {in }}-\dot{E} x_{\text {out }}-\dot{W}_{S T}$ & $\psi_{S T}=\frac{W_{S T}}{E x_{i n}-E x_{o u t}}$ \\
\hline Condenser & $\dot{E} x_{C o n d}^{D}=\sum \dot{E} x_{\text {in }}-\sum \dot{E} x_{\text {out }}$ & $\psi_{\text {Cond }}=1-\frac{E x_{\text {Cond }}}{E x_{i n}}$ \\
\hline Pump & $\dot{E x_{\text {pump }}^{D}}=\dot{E} x_{\text {in }}-\dot{E} x_{\text {out }}+\dot{W}_{\text {Pump }}$ & $\psi_{\text {pump }}=\frac{\dot{E} x_{o u t}-E x_{i n}}{\dot{W}_{\text {pump }}}$ \\
\hline Boiler & $\dot{E} x_{\text {Boiler }}^{D}=\sum \dot{E} x_{\text {in }}+\dot{E} x_{\text {fuel }}-\sum \dot{E} x_{\text {out }}$ & $\psi_{\text {Boiler }}=\frac{E x_{\text {water }, \text { out }}-E x_{\text {water }, \text { in }}}{E x_{f u e l}}$ \\
\hline
\end{tabular}

Table 2. Economical parameters.

\begin{tabular}{cc}
\hline Parameter & Value \\
\hline$i(\%)$ & 8 \\
$N$ (year) & 20 \\
$\varphi$ & 1.06 \\
$h r(\mathrm{~h})$ & 8000 \\
\hline
\end{tabular}

Cost balance and auxiliary equations of each component are shown in Table 3.

Several parameters are defined to compare exergoeconomic performance of different components. Average cost per unit exergy of fuel and product are defined as follows, respectively:

$$
\begin{aligned}
c_{F, k} & =\frac{\dot{C}_{F, k}}{\dot{E}_{F, k}} \\
c_{P, k} & =\frac{\dot{C}_{P, k}}{\dot{E}_{P, k}}
\end{aligned}
$$

Also the cost associated with the exergy destruction could be computed using the following equation:

$$
\dot{C}_{D, k}=c_{F, k} \dot{E}_{k}^{D}
$$

By using these parameters, some other variables could be defined. The relative cost difference of a component is defined as:

$$
r_{k}=\frac{c_{P, k}-c_{F, k}}{c_{F, k}}
$$

The difference is due to the cost rate associated with investment cost and exergy destruction cost. Also another parameter is defined as exergoeconomic factor and expressed as follows:

$$
f_{k}=\frac{\dot{Z}_{k}}{\dot{Z}_{k}+\dot{C}_{D, k}}
$$

This parameter shows the importance of investment cost in the sum of exergy destruction cost and investment cost.

\section{Results and discussion}

To perform energy and exergy analyses, a simulation code has been developed in Matlab. Energy and mass balances for each component are applied and thermodynamic properties of all streams are calculated based on IAPWS IF-97. Table 4 shows thermodynamic properties of all streams for the base case condition. It is worth mentioning that a gland steam condenser is used in real cycle of the plant between points 9 and 10 to increase feedwater temperature using steam leakages from the turbine. This component is neglected in thermodynamic modeling of the plant and a temperature difference is applied in the model between points 9 and 10, so that the developed model is consistent with the actual plant.

Exergy destruction and exergy efficiency of each component are calculated using equations in Table 1 and known thermodynamic properties. Table 5 shows exergy destruction of each component. As could be seen, boiler due to chemical reactions has the highest rate of exergy destruction and constitutes nearly $85 \%$ of the total exergy destruction of the system. Preheating the air, fuel and water could decrease the boiler's exergy destruction. Usually air and fuel are preheated using the heat of boiler outlet flue gas. The heat source for preheating feedwater is the steam extracted from the turbine. Although this method decreases the generated power of the turbine, it increases the plant's efficiency. Therefore, lower fuel is consumed and as a result lower emissions are produced. After boiler, the highest rate of exergy destruction is belonged to the turbine and condenser which have $8 \%$ and $5 \%$ of the total exergy destruction of the plant. Also exergy destructed in feedwater heaters and pumps are negligible compared to the other components as they are responsible for only $1.5 \%$ of total exergy destruction.

Figure 4 shows exergy efficiency of all components and the whole plant. As shown, condenser and boiler have the lowest exergy efficiencies. Also high pressure feedwater heaters have higher exergy efficiency than low pressure feedwater heaters. This is because that in these feedwater heaters, temperature difference between cold and hot streams is lower than the low pressure ones. Also the plants total exergy efficiency is $33.83 \%$.

Detailed exergoeconomic results are shown in Table 6 . In exergoeconomic analysis, more attention should be paid to component which has the highest rate of $\dot{Z}+\dot{C}_{D}$. Based on the results shown in Table 6, boiler, turbine and condenser have the highest value of $\dot{Z}+\dot{C}_{D}$, respectively. Therefore any effort to increase the performance of the plant should be applied to these components. Among the feedwater heaters, FWH 3 has the highest value of $\dot{Z}+\dot{C}_{D}$. Also the value of exergoeconomic factor in the 
A.M. Khoshkar Vandani et al.: Mechanics \& Industry 18, 224 (2017)

Table 3. Cost balance and auxiliary equations of each component.

\begin{tabular}{|c|c|c|}
\hline Component & Cost rate balance & Auxiliary equation \\
\hline Boiler & $\dot{C}_{16}+\dot{C}_{a i r}+\dot{C}_{\text {fuel }}+\dot{Z}_{\text {boiler }}=\dot{C}_{1}+\dot{C}_{Q, \text { boiler }}$ & $c_{q}=c_{f u e l}$ \\
\hline Steam turbine & $\dot{C}_{1}+\dot{Z}_{S T}=\dot{C}_{2}+\dot{C}_{3}+\dot{C}_{4}+\dot{C}_{5}+\dot{C}_{6}+\dot{C}_{7}+\dot{C}_{S T}$ & $\begin{array}{l}c_{2}=c_{1}, c_{3}=c_{1}, c_{4}=c_{1} \\
c_{5}=c_{1}, c_{6}=c_{1}, c_{7}=c_{1}\end{array}$ \\
\hline Condenser & $\dot{C}_{7}+\dot{C}_{25}+\dot{C}_{26}+\dot{Z}_{\text {cond }}=\dot{C}_{8}+\dot{C}_{27}$ & $c_{8}=c_{7}+c_{25} c_{26}=0$ \\
\hline Pump 1 & $\dot{C}_{8}+\dot{C}_{p u m p 1}+\dot{Z}_{p u m p 1}=\dot{C}_{9}$ & $c_{p u m p 1}=c_{S T}$ \\
\hline FWH \#1 & $\dot{C}_{10}+\dot{C}_{23}+\dot{C}_{24}+\dot{Z}_{F W H 1}=\dot{C}_{11}+\dot{C}_{25}$ & $c_{25}=c_{23}+c_{24}$ \\
\hline FWH \#2 & $\dot{C}_{11}+\dot{C}_{22}+\dot{Z}_{F W H 2}=\dot{C}_{12}+\dot{C}_{23}$ & $c_{22}=c_{23}$ \\
\hline FWH \#3 & $\dot{C}_{12}+\dot{C}_{20}+\dot{C}_{21}+\dot{Z}_{F W H 3}=\dot{C}_{13}$ & \\
\hline FWH \#4 & $\dot{C}_{14}+\dot{C}_{18}+\dot{C}_{19}+\dot{Z}_{F W H 4}=\dot{C}_{15}+\dot{C}_{20}$ & $c_{20}=c_{18}+c_{19}$ \\
\hline FWH \#5 & $\dot{C}_{15}+\dot{C}_{17}+\dot{Z}_{F W H 5}=\dot{C}_{16}+\dot{C}_{18}$ & $c_{18}=c_{17}$ \\
\hline Pump 2 & $\dot{C}_{13}+\dot{C}_{\text {pump } 2}+\dot{Z}_{\text {pump } 2}=\dot{C}_{14}$ & $c_{\text {pump } 2}=c_{S T}$ \\
\hline Pipe 1 & $\dot{C}_{6}+\dot{Z}_{p i p e 1}=\dot{C}_{24}+\dot{C}_{p i p e 1}$ & $c_{\text {pipe } 1}=c_{6}$ \\
\hline Pipe 2 & $\dot{C}_{5}+\dot{Z}_{\text {pipe } 2}=\dot{C}_{22}+\dot{C}_{\text {pipe } 2}$ & $c_{\text {pipe } 2}=c_{5}$ \\
\hline Pipe 3 & $\dot{C}_{4}+\dot{Z}_{\text {pipe } 3}=\dot{C}_{21}+\dot{C}_{\text {pipe } 3}$ & $c_{\text {pipe } 3}=c_{4}$ \\
\hline Pipe 4 & $\dot{C}_{3}+\dot{Z}_{\text {pipe } 4}=\dot{C}_{19}+\dot{C}_{\text {pipe } 4}$ & $c_{\text {pipe } 4}=c_{3}$ \\
\hline Pipe 5 & $\dot{C}_{2}+\dot{Z}_{\text {pipe } 5}=\dot{C}_{17}+\dot{C}_{\text {pipe } 5}$ & $c_{\text {pipe } 5}=c_{2}$ \\
\hline
\end{tabular}

Table 4. Thermodynamic properties of each stream for base condition.

\begin{tabular}{cccccc}
\hline Stream & $P($ bar $)$ & $T\left({ }^{\circ} \mathrm{C}\right)$ & $h\left({\left.\mathrm{~kJ} . \mathrm{kg}^{-1}\right)} s\left(\mathrm{~kJ}^{\mathrm{kg}}{ }^{-1} . \mathrm{K}^{-1}\right)\right.$ & $\dot{m}\left(\mathrm{~kg} . \mathrm{s}^{-1}\right)$ \\
\hline 1 & 87.198 & 510.000 & 3415.766 & 6.710 & 91.439 \\
2 & 33.640 & 389.636 & 3201.387 & 6.828 & 6.317 \\
3 & 17.416 & 308.361 & 3050.481 & 6.875 & 6.564 \\
4 & 6.474 & 203.043 & 2854.873 & 6.943 & 4.818 \\
5 & 2.668 & 129.573 & 2708.507 & 7.003 & 4.920 \\
6 & 0.774 & 92.584 & 2533.787 & 7.090 & 4.668 \\
7 & 0.085 & 42.588 & 2299.303 & 7.324 & 64.151 \\
8 & 0.085 & 42.588 & 178.356 & 0.607 & 73.739 \\
9 & 6.848 & 42.677 & 179.266 & 0.608 & 73.739 \\
10 & 6.848 & 50.677 & 212.743 & 0.712 & 73.739 \\
11 & 6.435 & 87.870 & 368.460 & 1.168 & 73.739 \\
12 & 6.021 & 124.420 & 522.850 & 1.575 & 73.739 \\
13 & 6.021 & 158.969 & 671.094 & 1.932 & 91.439 \\
14 & 97.714 & 160.848 & 684.552 & 1.940 & 91.439 \\
15 & 97.300 & 201.968 & 864.565 & 2.337 & 91.439 \\
16 & 96.887 & 237.195 & 1025.109 & 2.663 & 91.439 \\
17 & 31.285 & 386.496 & 3198.387 & 6.855 & 6.317 \\
18 & 31.285 & 204.740 & 874.347 & 2.373 & 6.317 \\
19 & 16.197 & 305.579 & 3047.481 & 6.902 & 6.564 \\
20 & 16.197 & 166.400 & 703.962 & 2.005 & 12.881 \\
21 & 6.021 & 200.600 & 2851.873 & 6.969 & 4.818 \\
22 & 2.484 & 127.204 & 2705.507 & 7.028 & 4.920 \\
23 & 2.484 & 93.430 & 391.535 & 1.232 & 4.920 \\
24 & 0.719 & 90.654 & 2530.787 & 7.113 & 4.668 \\
25 & 0.719 & 56.230 & 235.432 & 0.784 & 9.588 \\
26 & 0.893 & 17.700 & 74.375 & 0.264 & 3265.563 \\
27 & 0.893 & 27.700 & 116.208 & 0.405 & 3265.563 \\
\hline & & & & &
\end{tabular}

first three feedwater heaters is higher than the last two ones.

Equations (15) and (16) can help to understand that how the sum of investment cost and exergy destruction cost affects the exergoeconomic performance of the components. As shown in Table 6 , the highest values of relative cost difference occur in condenser and boiler, respectively. Based on value of $f$ for these components, for the condenser, almost $85 \%$ of the cost difference between in- let and outlet streams is because of exergy destruction, while for the boiler, exergy destruction is only responsible for about $45 \%$ of the cost difference. Therefore it could be concluded that decreasing exergy destruction in these components could have a considerable effect on the plant's exergoeconomic performance. After condenser and boiler, the highest value of $r$ belongs to the first and second feedwater heaters. A high value of exergoeconomic factor for these components reveals that investment cost 


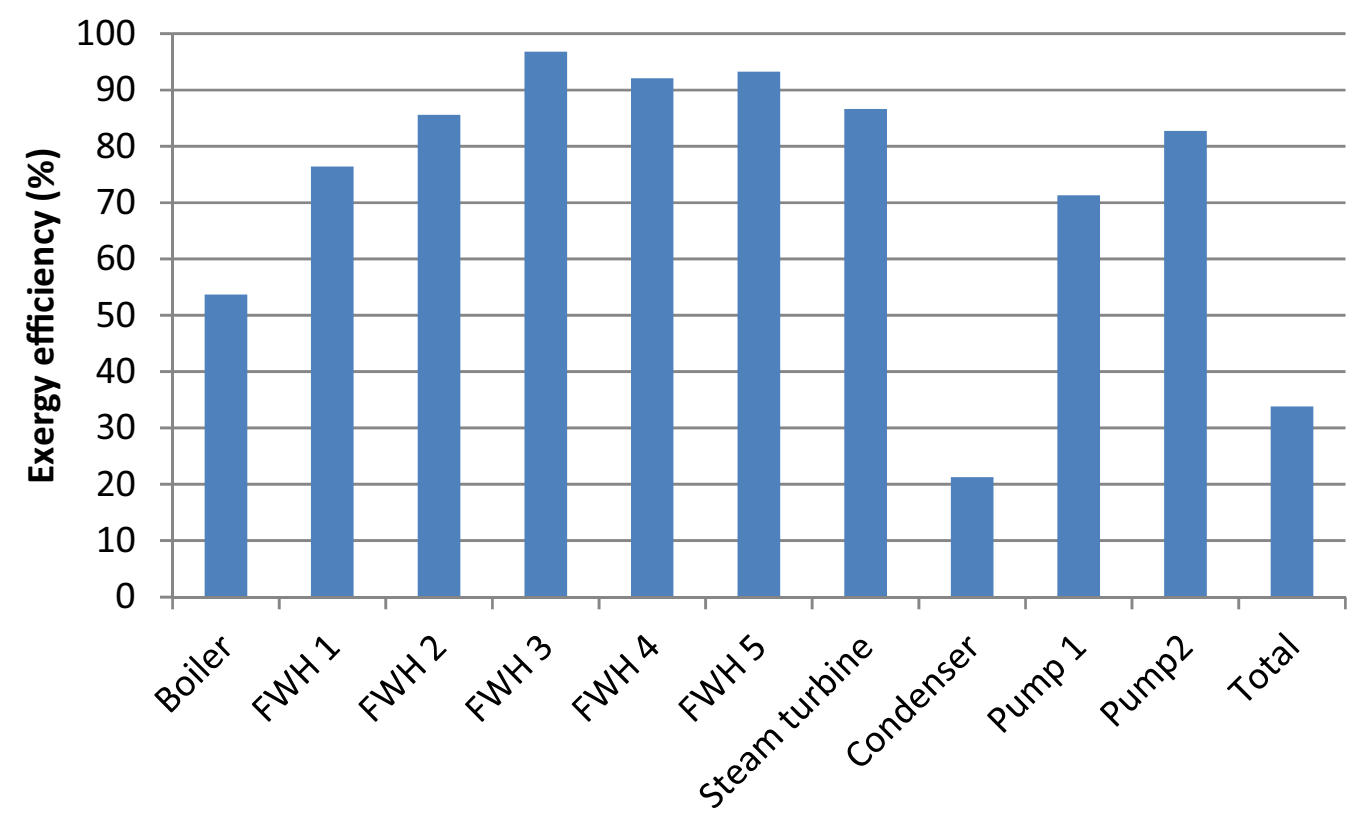

Fig. 4. Exergy efficiency of each component.

Table 5. Exergy destruction of each component.

\begin{tabular}{cc}
\hline Component & Exergy destruction $(\mathrm{kW})$ \\
\hline Boiler & 138205.268 \\
FWH 1 & 530.062 \\
FWH 2 & 444.795 \\
FWH 3 & 335.674 \\
FWH 4 & 510.271 \\
FWH 5 & 435.297 \\
Steam turbine & 13247.615 \\
Condenser & 8483.566 \\
Pump 1 & 19.261 \\
Pump2 & 212.537 \\
Total & 162424.346 \\
\hline
\end{tabular}

has the dominant effect in the relative cost difference. Therefore to decrease the cost difference, the investment cost should be lowered. This could be done by reducing the heat transfer area for these feedwater heaters, which leads to a reduction in their exergetic performance. But, since the effect of investment cost is higher than the exergy destruction cost, in general it leads to a better exergoeconomic performance. It's worth mentioning that the lowest values of $f$ occur in pumps which shows the importance of exergy destruction cost in these components.

\subsection{Optimization}

Optimization techniques could be used to achieve the best performance of the plant. Genetic algorithm (GA) is one of the best optimization techniques which has the capability of dealing with non-linear problems. GA was developed by Holland [27] and is based on natural genetics. It follows the "survival of the fittest" theory stated for the first time by Charles Darwin. To perform the optimization, GA produces a population of chromosomes randomly and then evaluates each individual in the population. The fittest individuals are then selected to produce next generation by mating procedure (crossover and mutation). This trend continues until the optimal solution of the problem is found. The flowchart of genetic algorithm process is shown in Figure 5. More explanation about GA could be found in Reference [28,29].

\subsubsection{Objective functions}

To perform the optimization, two objective functions are defined. The first one is the exergy efficiency of the plant which is defined as:

$$
\operatorname{Max} \psi=\frac{\dot{W}_{n e t}}{\dot{m}_{f u e l} \xi L H V}
$$

where $L H V$ is the lower heating value of the fuel and the other one is total product cost rate, which is defined as follows:

$$
\operatorname{Min} \dot{C}_{P, t o t}=\dot{C}_{F, t o t}+\dot{Z}_{t o t}
$$

The two considered objective functions are conflicting, such that a system with low efficiency is usually a cheap one, whereas the cost of a more efficient system is high. To have a bright insight about the behavior of these objective functions, a multi-objective optimization will be carried out along with the single objective one. It must be mentioned that in a multi-objective optimization, the optimal points are a set of values and it is the task of an expert to choose from these values according to their needs. 
A.M. Khoshkar Vandani et al.: Mechanics \& Industry 18, 224 (2017)

Table 6. Exergoeconomic results of the base case.

\begin{tabular}{cccccccc}
\hline Components & $c_{F}(\$ / \mathrm{GJ})$ & $c_{P}(\$ / \mathrm{GJ})$ & $\dot{C}_{D}(\$ /$ year $)$ & $\dot{Z}(\$ /$ year $)$ & $\dot{Z}+\dot{C}_{D}(\$ /$ year $)$ & $f(\%)$ & $r(\%)$ \\
\hline Boiler & 3 & 11.8284 & $1.3075 \times 10^{7}$ & $1.7853 \times 10^{7}$ & $3.0928 \times 10^{7}$ & 57.7223 & 294.2813 \\
FWH 1 & 12.2631 & 22.7506 & $2.0499 \times 10^{5}$ & $3.6309 \times 10^{5}$ & $5.6808 \times 10^{5}$ & 63.9153 & 85.5209 \\
FWH 2 & 12.7305 & 19.1809 & $1.7857 \times 10^{5}$ & $3.5975 \times 10^{5}$ & $5.3832 \times 10^{5}$ & 66.8279 & 50.6693 \\
FWH 3 & 18.3742 & 20.2430 & $1.9451 \times 10^{5}$ & $4.0531 \times 10^{5}$ & $5.9982 \times 10^{5}$ & 67.5726 & 10.1709 \\
FWH 4 & 9.5503 & 10.7062 & $1.5368 \times 10^{5}$ & $6.2300 \times 10^{4}$ & $2.1598 \times 10^{5}$ & 28.8448 & 12.1026 \\
FWH 5 & 12.6517 & 13.8351 & $1.7368 \times 10^{5}$ & $5.0650 \times 10^{4}$ & $2.2433 \times 10^{5}$ & 22.5786 & 9.3539 \\
Steam turbine & 12.5551 & 14.8215 & $5.2452 \times 10^{6}$ & $8.7814 \times 10^{5}$ & $6.1233 \times 10^{6}$ & 14.3407 & 18.0516 \\
Condenser & 11.9466 & 65.5548 & $3.1962 \times 10^{6}$ & $6.8447 \times 10^{5}$ & $3.8806 \times 10^{6}$ & 17.6382 & 448.7311 \\
Pump 1 & 14.8215 & 21.283 & $9.0027 \times 10^{3}$ & $7.4356 \times 10^{2}$ & $9.7462 \times 10^{3}$ & 7.6292 & 43.5954 \\
Pump 2 & 14.8215 & 18.0986 & $9.9342 \times 10^{4}$ & $5.8662 \times 10^{3}$ & $1.0520 \times 10^{5}$ & 5.5758 & 22.1105 \\
\hline
\end{tabular}

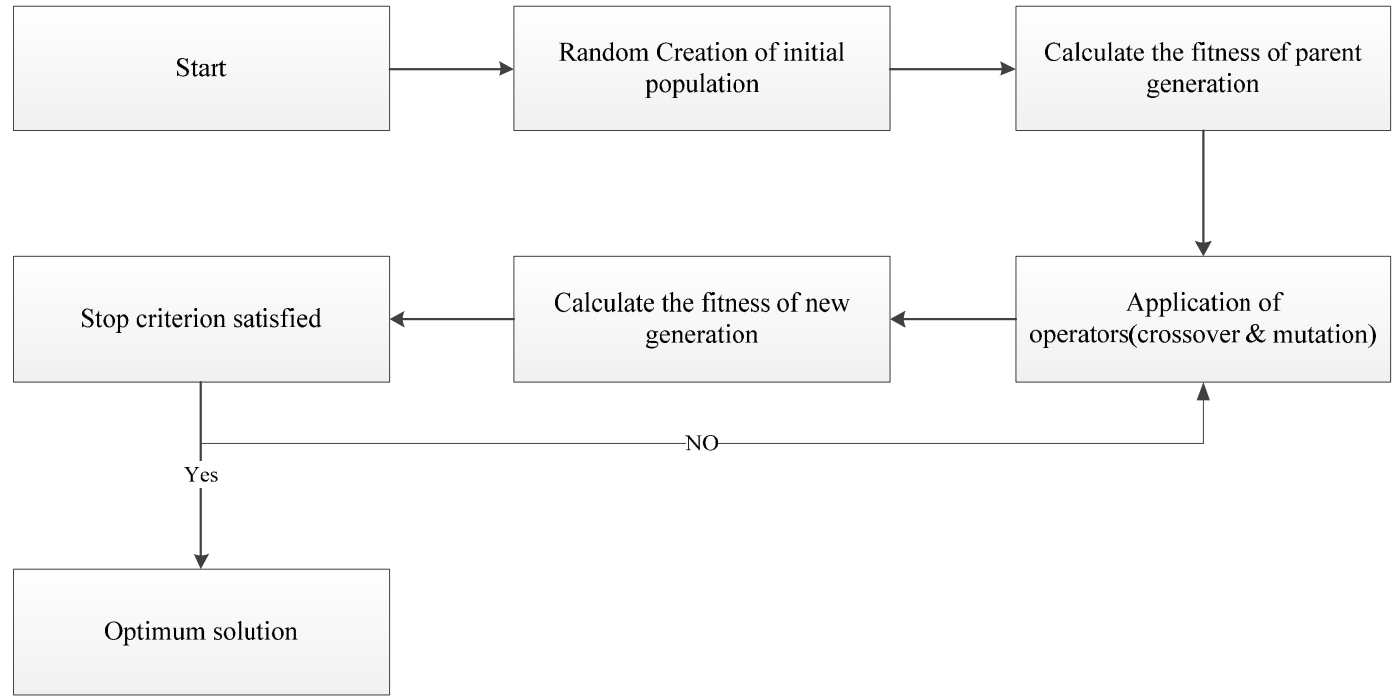

Fig. 5. Flowchart of genetic algorithm optimization.

\subsubsection{Decision variables}

The most effective parameters on the performance of a steam turbine power plant are outlet pressure and temperature of the boiler, extraction pressures and condenser pressure. Outlet pressure and temperature of the boiler are selected based on turbine's specification. Each industrial turbine has its own pressure and temperature limits, selected based on blades strength. In this study, it is assumed that the turbine's blade is not able to bear any increment in the inlet pressure and temperature of the turbine. Also working pressure of the condenser is a function of cooling water inlet temperature. Since the cooling tower operation is not considered in this study, the condenser pressure is assumed to be constant. As a result, only extraction pressures are considered as decision variables. Figures 6 and 7 show the effect of these parameters on the plants exergy efficiency. To study the effect of each decision variable, other parameters are kept constant. As could be seen, for each extraction pressure there is an optimum value which results the highest exergy efficiency. Also Figure 8 shows the variation of product cost rate versus extraction pressure for the 5th, 4th and 3rd FWHs. It could be clearly seen that the product cost rate is minimized for a specific value of each extraction pressure.

In this study, each decision variable is defined in a way that its pressure is higher than the previous extraction and also all extraction pressures are between the inlet and outlet pressure of the turbine. Therefore the above constrain could be expressed as follows:

$$
\begin{aligned}
P_{\text {turbine, inlet }}>P_{\mathrm{FWH} 5}> & P_{\mathrm{FWH} 4}>P_{\mathrm{FWH} 3}>P_{\mathrm{FWH} 2} \\
& >P_{\mathrm{FWH} 1}>P_{\text {condenser }}
\end{aligned}
$$

\subsubsection{Optimization results}

Single objective optimization is performed on the plant for the base case and the results are shown in Table 7 .

As seen from Table 7, optimum extraction pressures are different in the two objective functions. In the first objective function, the aim is to reach to the maximum exergy efficiency. Using the optimum values, exergy efficiency reaches to $33.9313 \%$, which shows nearly $0.3 \%$ increase with respect to the base case condition. Although this optimization increases the exergy efficiency of the system, but it increases the product cost rate of the system as 
A.M. Khoshkar Vandani et al.: Mechanics \& Industry 18, 224 (2017)

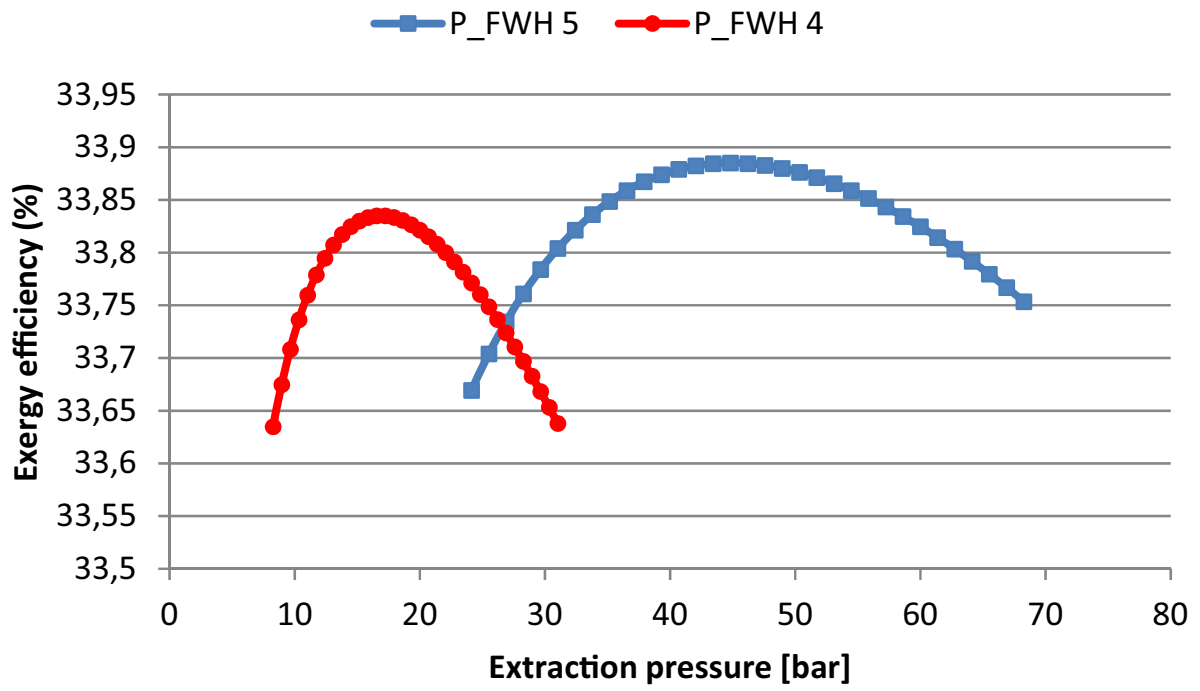

Fig. 6. Effect of extraction pressure of 4 th and 5th FWH on the plant's exergy efficiency.

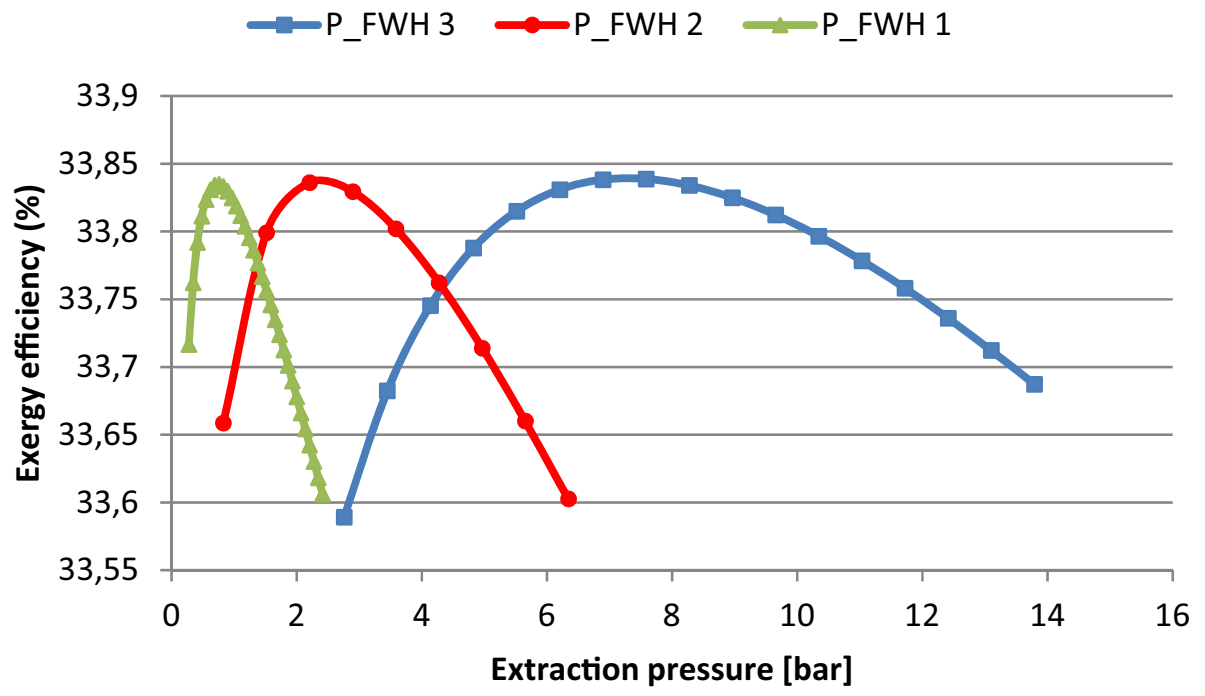

Fig. 7. Effect of extraction pressure of 1st, 2nd and 3rd FWH on the plant's exergy efficiency.

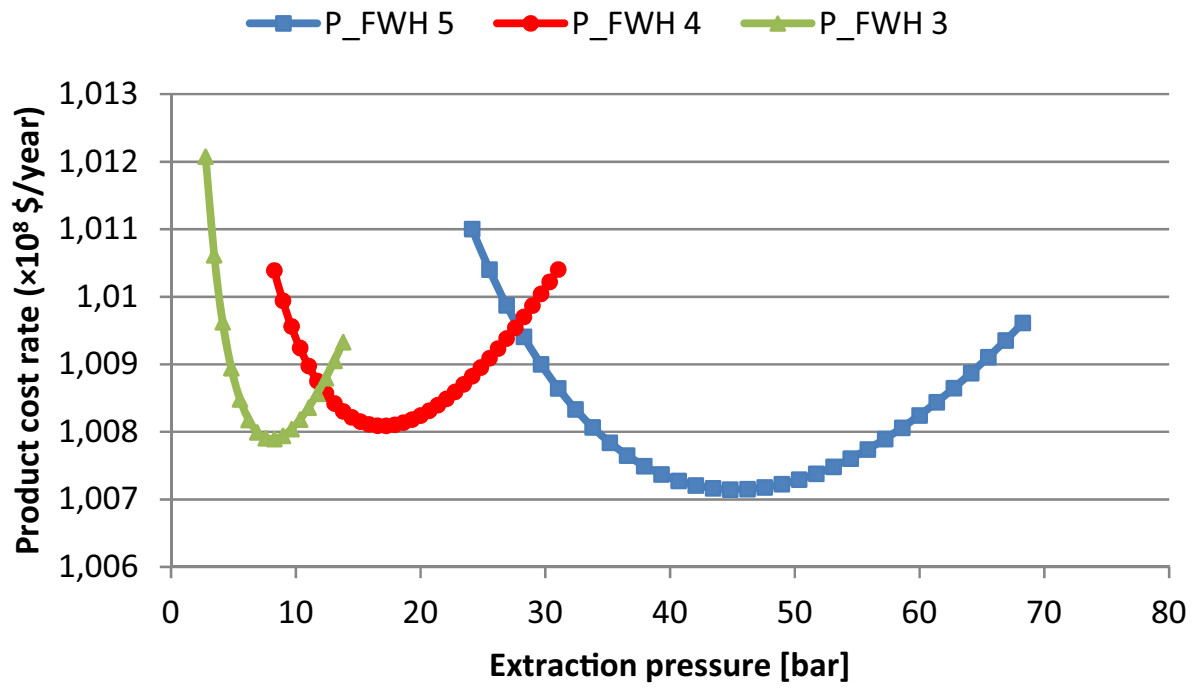

Fig. 8. Effect of extraction pressure of 3rd, 4th and 5th FWH on product cost rate of the plant. 
A.M. Khoshkar Vandani et al.: Mechanics \& Industry 18, 224 (2017)

Table 7. Results of single objective optimization for the base case.

\begin{tabular}{ccc}
\hline Decision variable & Maximizing exergy efficiency & Minimizing product cost rate \\
\hline Extraction pressure of FWH 1 (bar) & 0.8435 & 0.2757 \\
Extraction pressure of FWH 2 (bar) & 3.3790 & 0.7584 \\
Extraction pressure of FWH 3 (bar) & 10.8632 & 6.8147 \\
Extraction pressure of FWH 4 (bar) & 27.3258 & 24.2529 \\
Extraction pressure of FWH 5 (bar) & 55.1423 & 53.5962 \\
Exergy efficiency (\%) & 33.9313 & 33.7399 \\
Product cost rate $\left(\times 10^{8} \$\right.$ year $)$ & 1.0104 & 0.98367 \\
\hline
\end{tabular}

well. While in the base case condition, product cost rate of the plant was equal to $1.008 \times 10^{8} \$$ /year, after exergy efficiency optimization it reaches to $1.0104 \times 10^{8} \$ /$ year which shows a $0.228 \%$ increase. Also, as it was mentioned before, optimizing the plant in terms of exergy efficiency leads to a decrease in fuel consumption rate. Before the optimization, fuel mass flow was $5.1423 \mathrm{~kg} . \mathrm{s}^{-1}$ which reduced to $4.8395 \mathrm{~kg} / \mathrm{s}$. This reduction in fuel consumption results to an increase in the exergy efficiency of the boiler and a decrease in exergy destruction of this component. As shown in Figure 4 and Table 5, boiler exergy efficiency and exergy destruction are equal to $53.61 \%$ and $1.3851 \times 10^{5} \mathrm{~kW}$, for the current operating condition, while they reaches to $56.94 \%$ and $1.2955 \times 10^{5} \mathrm{~kW}$, respectively, after optimization. Decrement in boiler exergy destruction reduces the exergy destruction cost of boiler by $6.47 \%$. Therefore the exergoeconomic factor of boiler from $57.66 \%$ reaches to $59.29 \%$. This indicates that the effect of investment cost rate is increased in $\dot{Z}+\dot{C}_{D}$

In the second single objective optimization, product cost rate of the plant is minimized. The results show that performing the optimization reduces the product cost rate of the plant by $2.42 \%$, while exergy efficiency of the plant decreases simultaneously by $0.26 \%$ which again shows the conflict nature of the two selected objective functions. Although performing this optimization leads to some thermodynamic improvements of the system, these improvements are lower than the exergy efficiency maximization, because the focus is on the minimization of product cost rate. For example, reduction in fuel mass flow rate and boiler exergy destruction in the first optimization was $5.88 \%$ and $6.47 \%$, respectively, while in the second optimization these reductions are equal to $5.51 \%$ and $6.07 \%$, which are lower than the previous ones.

To investigate the effect of adding a new feedwater heater, optimization process is applied to both cases shown in Figure 2 (case 1) and Figure 3 (case 2) and the results are shown in Table 8.

Comparison of the results in Tables 7 and 8 reveals that in both cases, the optimum exergy efficiency is higher than the base case, but optimum value of product cost rate in case 1 is higher than the base case and in case 2 is lower than the base case. Also between cases 1 and 2, maximum exergy efficiency of case 1 is higher than case 2 , but minimum product cost rate of case 2 is lower than case 1 . Based on these results, it could be concluded that if the purpose is to achieve the highest exergy efficiency, case 1 configuration should be adopted for the plant, but if the goal is to reduce the product cost rate, then case 2 configuration results in better economic aspects.

The best thermodynamic performance occurs in exergy efficiency maximization in case 1 , where it reduces the fuel mass flow rate and boilers exergy destruction by $7.97 \%$ and $7.29 \%$, respectively. Also total product cost rate in the optimization of case 2 decreases to $0.9821 \times 10^{9} \$ /$ year which is reduced by $2.57 \%$.

To get a better insight about the behavior of the two objective functions, a multi-objective optimization is performed on the two selected scenarios along with the base case. The results are shown in Figure 9. The one shown in blue is the base case optimization, while the red and green ones are related to case 1 and case 2, respectively. The horizontal axis represents the exergy efficiency and since both new cases are in the right hand side of the base case in the graph, therefore in both cases, exergy efficiency is higher than the base case. But the value of the product cost rate objective function is different in the two selected cases. It could be clearly seen that case 1 leads to higher product cost rate. In general it could be suggested that case 2 has better performance than case 1 , as the exergy efficiency increases and the product cost rate reduces simultaneously.

\section{Conclusion}

In this study, a new feedwater heater is added to a steam power plant to investigate its exergoeconomic effect on the cycle. To do this, two configurations are defined. In the first one, the new feedwater heater is placed before FWH 1 (case 1) and in the second one the new feedwater heater is placed after FWH 5 (case 2). An optimization algorithm is applied to each of these cases and the results are compared. The main conclusions are summarized as below:

- In base case condition, boiler has the highest rate of exergy destruction and product cost rate. Nearly $85 \%$ of total exergy destruction is occurred in boiler. Also after condenser, the lowest exergy efficiency is belonged to the boiler.

- In base case condition, exergy efficiency optimization of the plant (before adding the new feedwater heater) increases the exergy efficiency by $0.3 \%$. This increment in exergy efficiency is achieved by reducing the fuel consumption. Also in exergoeconomic optimization, product cost rate is decreased by $2.42 \%$. 
A.M. Khoshkar Vandani et al.: Mechanics \& Industry 18, 224 (2017)

Table 8. Optimization results of case 1 and 2 .

\begin{tabular}{ccccc}
\hline Parameter & \multicolumn{2}{c}{ Case 1 } & \multicolumn{2}{c}{ Case 2 } \\
\cline { 2 - 5 } & Max $\psi_{t o t}$ & Min $C_{P, t o t}$ & Max $\psi_{\text {tot }}$ & Min $C_{P, t o t}$ \\
\hline Extraction pressure of FWH 1 (bar) & 2.3161 & 0.7584 & 0.7806 & 0.2757 \\
Extraction pressure of FWH 2 (bar) & 6.6096 & 1.2410 & 2.8663 & 0.7584 \\
Extraction pressure of FWH 3 (bar) & 16.4559 & 10.2878 & 9.0033 & 5.2216 \\
Extraction pressure of FWH 4 (bar) & 34.2419 & 28.0634 & 22.5709 & 18.4838 \\
Extraction pressure of FWH 5 (bar) & 61.2555 & 54.5803 & 42.6167 & 39.5707 \\
Extraction pressure of new FWH (bar) & 0.6967 & 0.2757 & 58.1465 & 60.0810 \\
Exergy efficiency (\%) & 34.0842 & 33.8423 & 33.9890 & 33.8511 \\
Product cost rate $\left(\times 10^{8}\right.$ \$/year) & 1.0221 & 0.9910 & 1.0070 & 0.9821 \\
\hline
\end{tabular}

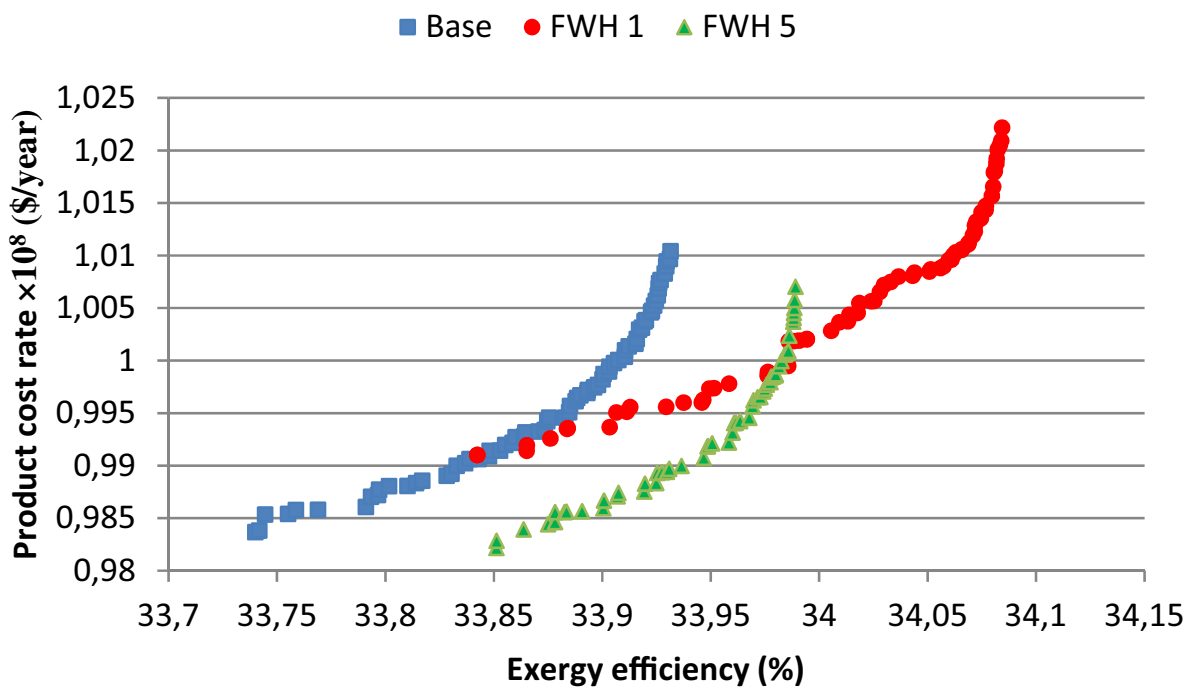

Fig. 9. Pareto frontier of the base case and the two selected cases.

- Optimization results of case 1 showed that the highest achievable exergy is equal to $34.0842 \%$ and the lowest achievable product cost rate is $0.991 \times 10^{8} \$ /$ year. While these values for case 2 are $33.989 \%$ and $0.9821 \times$ $10^{8} \$$ /year. In both cases, fuel consumption decreases, because adding the new feedwater heater increases the temperature of boiler inlet water. As a result, lower fuel is consumed and lower emissions are produced.

- Comparison of the results showed that case 2 can lead to better performance than case 1 as it reduces the product cost rate and increase the exergy efficiency, simultaneously. But in case 1 , both the exergy efficiency and product cost rate increases.

\section{References}

[1] Z. Hongbin, Exergy Analysis of a Steam Power Plant with Direct Air-Cooling System in China, in Power and Energy Engineering Conference, 2009. APPEEC 2009, Asia-Pacific, 2009, pp. 1-4

[2] I.H. Aljundi, Energy and exergy analysis of a steam power plant in Jordan, Appl. Thermal Eng. 29 (2009) 324-328

[3] M.A. Rosen, R. Tang, Improving steam power plant efficiency through exergy analysis: effects of altering excess combustion air and stack-gas temperature, Int. J. Exergy 5 (2008) 31-51
[4] H. Rosyid, R. Koestoer, N. Putra, A. Mohamad, Sensitivity analysis of steam power plant-binary cycle, Energy 35 (2010) 3578-3586

[5] A.M.K. Vandani, M. Bidi, F. Ahmadi, Exergy analysis and evolutionary optimization of boiler blowdown heat recovery in steam power plants, Energy Convers. Manag. 106 (2015) 1-9

[6] G. Xu, Y. Hu, B. Tang, Y. Yang, K. Zhang, W. Liu, Integration of the steam cycle and CO 2 capture process in a decarbonization power plant, Appl. Thermal Eng. 73 (2014) $277-286$

[7] O.K. Singh, S. Kaushik, Energy and exergy analysis and optimization of Kalina cycle coupled with a coal fired steam power plant, Appl. Thermal Eng. 51 (2013) 787800

[8] M. Suresh, K. Reddy, A.K. Kolar, Thermodynamic optimization of advanced steam power plants retrofitted for oxy-coal combustion, J. Eng. Gas Turbines Power 133 (2011) 063001

[9] Z. Li, Z.M. Li, Z.L. Yan, Energy and Exergy Analysis for Three Type 500MW Steam Power Plants, Appl. Mech. Mater. (2012) 1131-1136

[10] G. Xu, L. Zhou, S. Zhao, F. Liang, C. Xu, Y. Yang, Optimum superheat utilization of extraction steam in double reheat ultra-supercritical power plants, Appl. Energy (2015) 
[11] K. Ozdemir, A. Hepbasli, N. Eskin, Exergoeconomic analysis of a fluidized-bed coal combustor (FBCC) steam power plant, Appl. Thermal Eng. 30 (2010) 1621-1631

[12] V. Matawala, P. Prabhakaran, Exergoeconomic optimisation of steam power plant, Int. J. Exergy 10 (2012) 209-227

[13] M.H.K. Manesh, M. Amidpour, H.K.J. Abadi, Comparison of combined cycle and conventional steam power plant through energy level and thermoeconomic analysis, in ASME 2008 International Mechanical Engineering Congress and Exposition, 2008, pp. 819-846

[14] M. Ameri, P. Ahmadi, A. Hamidi, Energy, exergy and exergoeconomic analysis of a steam power plant: a case study, Int. J. Energy Res. 33 (2009) 499-512

[15] A. Mehrpanahi, S. Hossienalipour, K. Mobini, Investigation of the effects of repowering options on electricity generation cost on Iran steam power plants, Int. J. Sustainable Energy 32 (2013) 229-243

[16] A. Ganjehkaviri, M.M. Jaafar, S. Hosseini, Optimization and the effect of steam turbine outlet quality on the output power of a combined cycle power plant, Energy Convers. Manag. 89 (2015) 231-243

[17] L. Galanti, A. Franzoni, A. Traverso, A.F. Massardo, Existing large steam power plant upgraded for hydrogen production, Appl. Energy 88 (2011) 1510-1518

[18] S. Khanmohammadi, A.R. Azimian, S. Khanmohammadi, Exergy and exergo-economic evaluation of Isfahan steam power plant, Int. J. Exergy 12 (2013) 249-272

[19] R. Chacartegui, D. Sánchez, J. Becerra, A. Muñoz, T. Sánchez, Performance Analysis of a 565 MW Steam Power Plant, in ASME 2011 Turbo Expo: Turbine Technical Conference and Exposition, 2011, pp. 24272436
[20] S. Farhad, M. Saffar-Avval, M. Younessi-Sinaki, Efficient design of feedwater heaters network in steam power plants using pinch technology and exergy analysis, Int. J. Energy Res. 32 (2008) 1-11

[21] T.J. Kotas, The exergy method of thermal plant analysis: Elsevier, 2013

[22] A. Bejan, G. Tsatsaronis, M.J. Moran, Thermal Design Optimization: John Wiley \& Sons, 1996

[23] I. Dincer, Y.A. Cengel, Energy, entropy and exergy concepts and their roles in thermal engineering, Entropy 3 (2001) 116-149

[24] M. Ameri, P. Ahmadi, The study of ambient temperature effects on exergy losses of a heat recovery steam generator, in Challenges of Power Engineering and Environment, ed: Springer, 2007, pp. 55-60

[25] M. Kanoglu, I. Dincer, M.A. Rosen, Understanding energy and exergy efficiencies for improved energy management in power plants, Energy Policy 35 (2007) 3967-3978

[26] CEPCI, Chemical Engineering Plant Cost Index. Chem. Eng., 2014

[27] J.H. Holland, Adaptation in natural and artificial systems: an introductory analysis with applications to biology, control, and artificial intelligence: MIT press, 1992

[28] B. Coppin, Artificial intelligence illuminated: Jones \& Bartlett Learning, 2004

[29] M. Mitchell, An introduction to genetic algorithms: MIT press, 1998 